\title{
Research Integrity: Creating New Demands for the Training of Young Researchers?
}

\section{Sonia MR Vasconcelos}

Science Education Program/Medical Biochemistry Institute, Federal University of Rio de Janeiro, UFRJ

E-mail: svasconcelos@bioqmed.ufri.br

$\mathrm{L}$ ast year, the announcement that researchers from the physics community found that neutrinos (subatomic particles) could travel about 60 nanoseconds faster than light made international headlines. This revolutionary finding, which would challenge Albert Einstein's theory of relativity, was released on the ArXiv preprint server on 17 November, 2011 (1). The paper showed original data from OPERA (Oscillation Project with Emulsion-Racking Apparatus) collaboration. OPERA's collaborators produced a beam of neutrinos that travelled from the European Organization for Nuclear Research (CERN), in Switzerland, to Gran Sasso underground laboratory, in Italy, through $731 \mathrm{~km}$ of rock. The speed measured was apparently faster than that of light. However, cross-check measurements showed timing problems in the OPERA experiments, and a loose cable would have led to mismeasurements $(2,3)$.

In a recent Nature Editorial, they mention that "if the public learned one thing about physics last year, it was that a particle had been found that might travel faster than the speed of light... [however] when the error was discovered, physicists on the team wasted no time in publicly announcing the problem..." (4). According to Sergio Bertolucci, CERN research director, the OPERA episode "has given people the opportunity to see the scientific method in action an unexpected result was put up for scrutiny, thoroughly investigated and resolved in part thanks to collaboration between normally competing experiments." (5). Indeed, this OPERA episode offered the public the opportunity to learn a little bit about the nature of science. As Miller argues in his well read paper on the relationship between science and the public, "if we are entering a new age for public understanding of science, it is important that citizens get used to scientists arguing out controversial facts, theories, and issues." (6).

In a Euroscience blog post entitled Science is changing faster than a faster-than-light neutrino, Walton captures this single moment of science saying that "perhaps for the first time in history so far, the public have begun to get a feel for the infuriating situation research scientists find themselves in everyday when they get out of bed?" (7). Walton's views agree with those in the Nature editorial and seem to reflect the zeitgeist of $21^{\text {st }}$ century science. This perception is true when we look at the increasing role of the public in major discussions, for example, in large scientific meetings. The White House Office of Science and Technology Policy has recently announced that it would convene a Grand Challenges Conference, which would address grand topics such as global health, solar energy, electric vehicles, and many others that can "capture public imagination and increase support for public policies that foster science, technology, and innovation" (8). In Europe, The Euroscience Open Forum (ESOF), a biannual general science meeting held in leading European cities, has also looked at grand challenges. This year, the ESOF program includes sessions on the impact of ice sheet and ocean interactions on climate change, on emerging therapies for brain and retinal diseases, but also on how to motivate scientists to engage with the public, on research integrity and on ethics in research (9).

One may ask why the public, research integrity and ethics would be included in a meeting discussing grand challenges in today's science. We could perhaps say that coping with our time's grand challenges requires broader engagement with the public and depends on the level of accountability and trust the public has in the scientific process. This is a reasonable assumption if we consider how research claims have impacted society and influenced public opinion and confidence in science. This issue can be noted for example in the MMR [measles, mumps and rubella] vaccination and autism controversy. In this case, controversial research claims led to public outrage and mistrust, affecting the rates of vaccination, which fell dramatically for many years and led to disease outbreaks (10). The importance of public trust in science and their attitudes towards grand challenges is also noted in discussions on climate change research. According to James Hansen, director of NASA Goddard Institute for Space Studies, "public scepticism about the threat of man-made climate change has increased despite the growing scientific consensus". Hansen attributed this situation to leaked e-mails exchanged by climate scientists, from a server at the Climate Research Unit, at the University of East Anglia (11). 
In this current environment, research integrity, ethics in science, technology and innovation, and the confidence the public can develop in the research process are closely related. This is one of the major reasons why young researchers should be aware that the research environment has changed - so much so that "the professional practices of scientists are becoming increasingly scrutinized by the public, with greater expectations for accountability, integrity in research, and access to information." (12). As Frankel states, "this emerging environment poses new demands on current responsible conduct of research (RCR) education" and "as professional research practices evolve, so must the education options offered to scientists and their students." (13).

In Brazil, awareness that this emerging environment deserves more attention, especially from universities, is reflected in the recently launched Joint Statement on Research Integrity. This document, which resulted from the II Brazilian Meeting on Research Integrity, Science and Publication Ethics (II BRISPE) (14), recommends nine actions that can potentially help to change the scope of training of Brazilian undergraduate and graduate students when it comes to research integrity and RCR. Recommendations for broadening that scope are grounded on the fact that research integrity is closely related to notions of research excellence, public confidence and accountability in science.

At the closing session of the II BRISPE at the Pontifical Catholic University of Rio Grande Sul (PUCRS), Professor José Goldim argued that part of the joy of being in academia today is that whereas we are witnessing this shift in the research climate, we have the single opportunity to be sources of marked changes in the local, global and increasingly multidisciplinary academic setting. At the end of the session, I echoed his words. In this context, academic institutions in Brazil can make a difference if research integrity and RCR are taken as part of grand topics to be addressed in the training of students and young researchers.
References
1. Adam T. Measurement of the neutrino velocity with the OPERA detector in the CNGS beam. OPERA Collaboration. 2011. ArXiv: 1 109.4897 [hep-ex]

2. Brumfiel G. Neutrinos not faster than light. 2012.

3. Opera. Available at http://operaweb.Ings.infn.it/spip.php? rubrique 14\&lang=en

4. Cartlidge E. Error undoes faster-than-light neutrino results. Science Insider. Science 2012. Available at http://news.sciencemag.org/scienceinsider/2012/02/breaking-news-errorundoes-faster.html

5. Nature. No Shame. Nature 2012;484:287-88

6. CERN. OPERA experiment reports anomaly in flight time of neutrinos from CERN to Gran Sasso. Press Release. 2012. Available at http://press.web.cern.ch/press/pressreleases/ releases2011/pr19.11 e.html

7. Miller S. Public understanding of science at the crossroads. Public Understand Sci 2001;10:115-20.

8. Walton R. Science is changing faster than a faster-than-light neutrino. Euroscience.org 2011. Available at http://euroscientist.com/2011/11/how-science-is-changing-fasterthan-a-faster-than-light-neutrino/

9. The White House Office of Science and Technology Policy. 21 st Century Grand Challenges 2012. Available at http://www.whitehouse.gov/blog/2012/04/09/21 st-century-grandchallenges

10. The Euroscience Open Forum (ESOF). 2012. Available at http://esof2012.org/wpcontent/uploads/2012/07/ESOF2012_Programme.pdf

11. Burgess DC, Burges MA, Leask J. The MMR vaccination and autism controversy in United Kingdom 1998-2005: Inevitable community outrage or a failure of risk communication? Vaccine 2006;24:3921-8.

12. Gray R. Climate scientists are losing the public debate on global warming. The Telegraph. 2012. Available at http://www.telegraph.co.uk/earth/environment/ climatechange/9192494/Climate-scientists-are-losing-the-public-debate-on-globalwarming.html

13. Frankel M. The American Association for the Advancement of Science (AAAS). Professional Ethics Report 2011; 24:1-11.

14. Joint Statement on Research Integrity of the II Brazilian Meeting on Research Integrity Science and Publication Ethics. 2012. Available at http://www.iibrispe.coppe.ufri.br/images/ IIBRISPE/JoinStatement/JointStatementonResearchlntegrity_IIBRISPE_2012 English.pdf 